\title{
Individual or combined transcatheter arterial chemoembolization and radiofrequency ablation for hepatocellular carcinoma: a time-to-event meta-analysis
}

\author{
Chuang Jiang ${ }^{1}$, Gong Cheng ${ }^{2}$, Mingheng Liao ${ }^{1}$ and Jiwei Huang ${ }^{1 *}$
}

\begin{abstract}
Background: There is still some debate as to whether transcatheter arterial chemoembolization (TACE) plus radiofrequency ablation (RFA) is better than TACE or RFA alone. This meta-analysis aimed to compare the efficacy and safety of TACE plus RFA for hepatocellular carcinoma (HCC) with RFA or TACE alone.

Methods: We searched PubMed, MEDLINE, Embase, Cochrane Library, and CNKI (China National Knowledge Infrastructure) for all relevant randomized controlled trials and retrospective studies reporting overall survival (OS), recurrence-free survival (RFS), and complications of TACE plus RFA for HCC, compared with RFA or TACE alone.

Results: Twenty-one studies involving 3413 patients were included. TACE combined with RFA was associated with better OS (hazard ratio $[\mathrm{HR}]=0.62,95 \%$ confidence intervals $[\mathrm{Cl}]=0.55-0.71, P<0.001)$ and $\mathrm{RFS}(\mathrm{HR}=0.52,95 \% \mathrm{Cl}=$ 0.39-0.69, $P<0.001$ ) than TACE alone; compared with RFA alone, TACE plus RFA resulted in longer OS (HR $=0.63$, $95 \% \mathrm{Cl}=0.53-0.75, P<0.001)$ and $\mathrm{RFS}(\mathrm{HR}=0.60,95 \% \mathrm{Cl}=0.51-0.71, P<0.001)$. Subgroup analyses by tumor size also showed that combined treatment resulted in better OS and RFS compared with RFA alone in patients with HCC larger than $3 \mathrm{~cm}$. Combined treatment resulted in similar rate of major complications compared with TACE or RFA alone $(\mathrm{OR}=1.78,95 \% \mathrm{Cl}=0.99-3.20, P=0.05 ; \mathrm{OR}=1.00,95 \% \mathrm{Cl}=0.42-2.38, P=1.00$, respectively).

Conclusions: TACE combined with RFA was more effective for HCC than TACE alone. For patients with a tumor larger than $3 \mathrm{~cm}$, the combined treatment also achieved a better effect than RFA alone.
\end{abstract}

Keywords: Hepatocellular carcinoma, Transcatheter arterial chemoembolization, Radiofrequency ablation, Combined treatment, Meta-analysis

\section{Background}

Hepatocellular carcinoma (HCC) is the most common primary liver cancer [1], is the fourth leading cause of cancer death in the world, and ranks the fifth among all the diseases in the world [2]. Hepatocellular carcinoma often occurs in patients with a background of cirrhosis

\footnotetext{
* Correspondence: huang_jiweimd@163.com

1 Department of Liver Surgery, Liver Transplantation Center, West China Hospital, Sichuan University, Chengdu, Sichuan, China

Full list of author information is available at the end of the article
}

and is an important cause of death in patients with cirrhosis, and the common causes of cirrhosis vary from country to country, such as excessive alcohol intake [3], schistosomiasis infection, and nonalcoholic fatty liver disease (NAFLD) in developed regions [4], while in China, the main cause is hepatitis B infection (HBsAg+). There are multiple staging systems to assess HCC prognosis and guide treatment [5], such as Tumour, Node, Metastasis (TNM); The Cancer of the Liver Italian Program; the Hong Kong Liver Cancer staging system [6];

C C The Author(s). 2021 Open Access This article is licensed under a Creative Commons Attribution 4.0 International License, which permits use, sharing, adaptation, distribution and reproduction in any medium or format, as long as you give appropriate credit to the original author(s) and the source, provide a link to the Creative Commons licence, and indicate if changes were made. The images or other third party material in this article are included in the article's Creative Commons licence, unless indicated otherwise in a credit line to the material. If material is not included in the article's Creative Commons licence and your intended use is not permitted by statutory regulation or exceeds the permitted use, you will need to obtain permission directly from the copyright holder. To view a copy of this licence, visit http://creativecommons.org/licenses/by/4.0/ The Creative Commons Public Domain Dedication waiver (http://creativecommons.org/publicdomain/zero/1.0/) applies to the data made available in this article, unless otherwise stated in a credit line to the data. 
and the Barcelona Clinic Liver Cancer (BCLC) staging system, which is the most widely used staging system for hepatocellular carcinoma. Patients with hepatocellular carcinoma at each stage have one or more treatment options that are relatively most suitable. But with the diversification of treatment options, including surgical resection, radiofrequency ablation (RFA), transcatheter arterial chemoembolization (TACE), microwave ablation, targeted therapy, and transplantation, it is worth studying by comparing which one is the best, so as to identify candidates who are suitable for a certain treatment [1]. Surgical resection has been recommended for most HCC patients [7]. However, due to the absence of specific symptoms in the initial stage of HCC, early diagnosis is difficult, so less than $20 \%$ of patients have surgical indications at the time of diagnosis. While for earlystage HCC, the radiofrequency ablation (RFA) is microinvasive and with less pain, shorter length of hospital stay at a lower cost [8], and similar benefits to surgical resection, but there are always concerns of tumor residual which might lead to early tumor recurrence [912]. The effect of RFA is affected by tumor size and the "heat-sink" effect [13].

TACE has been applied in HCC patients for more than 40 years [14]. Though HCC is not sensitive to most systemic chemotherapy, adjuvant TACE after localized HCC treatment is related to better patient survival outcome according to previous researches [15-18] and meta-analysis [19]. As TACE could trigger tumor necrosis after tumor hypoxia, adjuvant TACE combined with RFA may theoretically bring about better outcomes. A number of published meta-analyses had compared adjuvant RFA with large HCC tumor after TACE therapy [20-22], but their results could hardly been utilized in directing clinical treatment because the complicated factors related to succeeding down-stage treatment could not be homogenized. Several years ago, Liu et al. published a meta-analysis of adjuvant TACE treatment after RFA [23], only seven studies were included. Many highquality studies have been published in recent years, providing more information for detailed statistical analysis. Thus, this up-to-date meta-analysis aimed to evaluate the effectiveness of adjuvant TACE therapy combined with RFA in improving the outcome of patients with primary HCC.

\section{Methods}

\section{Search strategy}

As of June 31, 2020, studies were identified through a search of PubMed, MEDLINE, Embase, Cochrane Library, and CNKI. The retrieval strategy included subject words and free words. We combined the terms such as "HCC," "hepatocellular carcinoma," or "liver cancer"; "radiofrequency ablation" or "RFA"; and "Therapeutic
Chemoembolization," "transarterial chemoembolization," "transcatheter arterial chemoembolization," or "TACE." No language limitations were imposed in our search.

\section{Inclusion and exclusion criteria}

Studies were included in the analysis if (1) either randomized controlled trials (RCTs) or observational studies comparing combination therapy of TACE and RFA versus RFA or TACE alone for HCC; (2) HCC can be diagnosed with CT or MRI if the typical characteristics are present; (3) full-text, or abstract and figures available; (4) providing outcome as OS or RFS, with comparisons between the outcomes of TACE and RFA with TACE or RFA alone; and (5) patients received comparable treatments except for TACE or RFA in specific settings. If studies were duplicates, the one with complete data was included.

Studies were excluded if they were published only in the form of case reports, editorials, reviews, and conference abstracts.

\section{Quality assessment}

The Cochrane Collaboration's tool was used to assess the risk of bias among RCTs, considering random sequence generation, allocation concealment, blinding of participants and personnel, blinding of outcome assessment, incomplete outcome data, and selective reporting [24]. Observational studies were assessed by the NewcastleOttawa Quality Assessment Scale (NOS) [25]. This score assesses studies according to the selection of patients in the exposed and the non-exposed group, comparability of the two groups, and outcome of the single studies. A study can be rated 0-9 stars based on these criteria while 6 stars or above was considered high quality in previous studies and was included in this review.

Publication bias was evaluated by funnel plots, Begg's test, and Egger's test [26]. The funnel plot is a widely used tool within meta-analysis for detecting publication bias [27]. It has the advantage of visually presenting the results through graphics, and the obvious asymmetry of funnel plot indicates a large publication bias in metaanalysis [28]; in the absence of bias, it should be a symmetrical funnel plot [29] but it cannot be quantitatively detected, and Begg's test and Egger's test can conduct a quantitative test of publication bias. When there were fewer included studies, Egger's test was more effective than Begg's test [30]. In order to make the detection of publication bias more comprehensive, we used the above three methods together to make a comprehensive assessment.

\section{Statistical extraction and analysis}

The hazard ratio (HR) and its 95\% confidence interval (CI) were used as an indicator of time-to-event to assess 
the pooled effects. HR and 95\% CI were extracted from the included studies. If both single factor and multivariate analysis data were available in the original research, the results of the multivariate analysis were selected to reduce the interference of confounding factors. If an article did not provide HR and 95\% CI for OS or RFS, we extracted the HR from Kaplan-Meier curves according to the method described by Tierney [31]. In addition, complications were compared by calculating odds ratio (OR) with 95\% CI. We used Cochrane's Q statistic to assess heterogeneity between studies [32]. The Q-test and $I^{2}$ were utilized to define the heterogeneity, according to the Cochrane Handbook. The value of $I^{2}$ ranges from 0 to $100 \%$, and the heterogeneity increases with the increase of value, a value of $I^{2}$ of $0-25 \%$ indicates insignificant heterogeneity, $25-50 \%$ indicates low heterogeneity, $50-75 \%$ indicates moderate heterogeneity, and $>75 \%$ indicates high heterogeneity [33, 34]. In cases of $P \geq 0.1$ or $I^{2}<50 \%$, indicating that heterogeneity was within the acceptable range, the fixed effects model was used to pool the results. Because the application condition of fixed effects model is more severe than that of random effects model. Only when the heterogeneity is within an acceptable range, the results obtained by using fixed effects model can be reliable; otherwise, the random effects model was used. In addition, funnel plots, Begg's test, and Egger's test were used to evaluate publication bias, and sensitivity analysis was used to test the stability of the pooled effects [35]. For all analyses, $P<0.05$ was considered statistically significant. RevMan 5.2 (Copenhagen: The Nordic Cochrane Centre, The Cochrane Collaboration, 2014) and Stata 12 (StataCorp LP, Stata Statistical Software, College Station, TX, USA) were used for the statistical analysis (Supplementary Figure 1).

\section{Results}

Study selection and quality evaluation

There were 1306 studies identified after searching PubMed, MEDLINE, Embase, Cochrane Library, and CNKI. Following the initial review, 262 repetitive documents were eliminated by automatic deduplication and manual removal. Reading of the title and abstract led to the exclusion of 977 studies. After the full text was read, 21 articles were finally included in the study based on reasonable criteria (Fig. 1). There were 10 studies comparing TACE+RFA and RFA alone for HCC, and 15 studies comparing TACE+RFA and TACE alone. Table 1 shows the basic characteristics of the 21 studies. As detailed in the Cochrane Handbook, three RCTs were evaluated with the Cochrane Collaboration's tool (Supplementary Figure 2). Because of problems such as treatment and ethics, double blindness is difficult to achieve in studies of this type. The 18 cohort studies were assessed with the NOS
(Supplementary Table 1). The scores of these studies are all greater than or equal to 7 points.

\section{Descriptive statistics analysis of clinicopathological characteristics}

Then, a descriptive statistics analysis of clinicopathological characteristics of patients in 21 included studies was performed (Supplementary Table 2). A total of 2339 patients were included in the TACE+RFA vsTACE group, while 1341 patients were included in the TACE+RFA vs RFA group. Because the indicators reported by various institutes are not exactly the same, when we make statistical analysis of an indicator, only the studies with reported related indicators were analyzed. For the TACE+ RFA vs TACE group, there were no statistical differences in age $(p=0.919)$, gender $(p=0.401), \mathrm{HBsAg}+(p=$ $0.097)$, and Child-Pugh classification $(p=0.188)$ between the groups. However, the proportion of countries in TACE+RFA group was Japan, Korea, and China which were $11.2 \%, 41.4 \%$, and $47.4 \%$, respectively, compared with TACE group's $8.6 \%, 47.3 \%$, and $44.1 \%$, respectively $(p=0.007)$; tumor size $(3.23 \pm 1.24$ vs $3.07 \pm 1.26, p=$ $0.03)$; HCV-Ab+ $(p=0.019)$. However, TACE+RFA vs RFA group also had a significant difference in proportion of countries $(10.7 \%, 45.7 \%, 43.6 \%$ vs $8.3 \%, 53.2 \%$, $38.5 \%, p=0.02)$, tumor size ( $3.66 \pm 1.64$ vs $4.03 \pm 1.66, p$ $<0.001)$, HCV-Ab+ $(p=0.04)$, and Child-Pugh classification $(p=0.013)$.

\section{Overall survival}

Ten studies including a total of 2339 patients compared the OS of TACE+RFA and TACE alone. The heterogeneity test showed $p=0.71, I^{2}=0 \%$. Therefore, the fixed effects model was selected to pool the HR of OS. The pooled result showed that the OS of TACE combined with RFA was better than that of TACE alone (HR = 0.62 , 95\% CI $0.55-0.71, p<0.001)$. TACE+RFA was associated with a $38 \%$ lower hazard of death than that of TACE alone (Fig. 2a) (Supplementary Table 3).

The OS of TACE+RFA was compared with that of RFA in eight studies that included a total of 1341 patients. The heterogeneity test showed $p=0.38, I^{2}=7 \%$. The fixed effects model was used to pool the results. The difference in OS was statistically significant $(\mathrm{HR}=0.63,95 \%$ CI $0.53-0.75$, $p<0.001$ ) (Fig. 2c) (Supplementary Table 3).

\section{Recurrence-free survival}

Only six studies, including 1037 patients, compared the RFS of TACE+RFA and TACE alone. The heterogeneity test showed $p=0.02, I^{2}=61 \%$. So, the random effects model was used to pool the results. The difference in the RFS was statistically significant $(\mathrm{HR}=0.52,95 \% \mathrm{CI}=$ 0.39-0.69, $p<0.001$ ) (Fig. 2b) (Supplementary Table 3). 


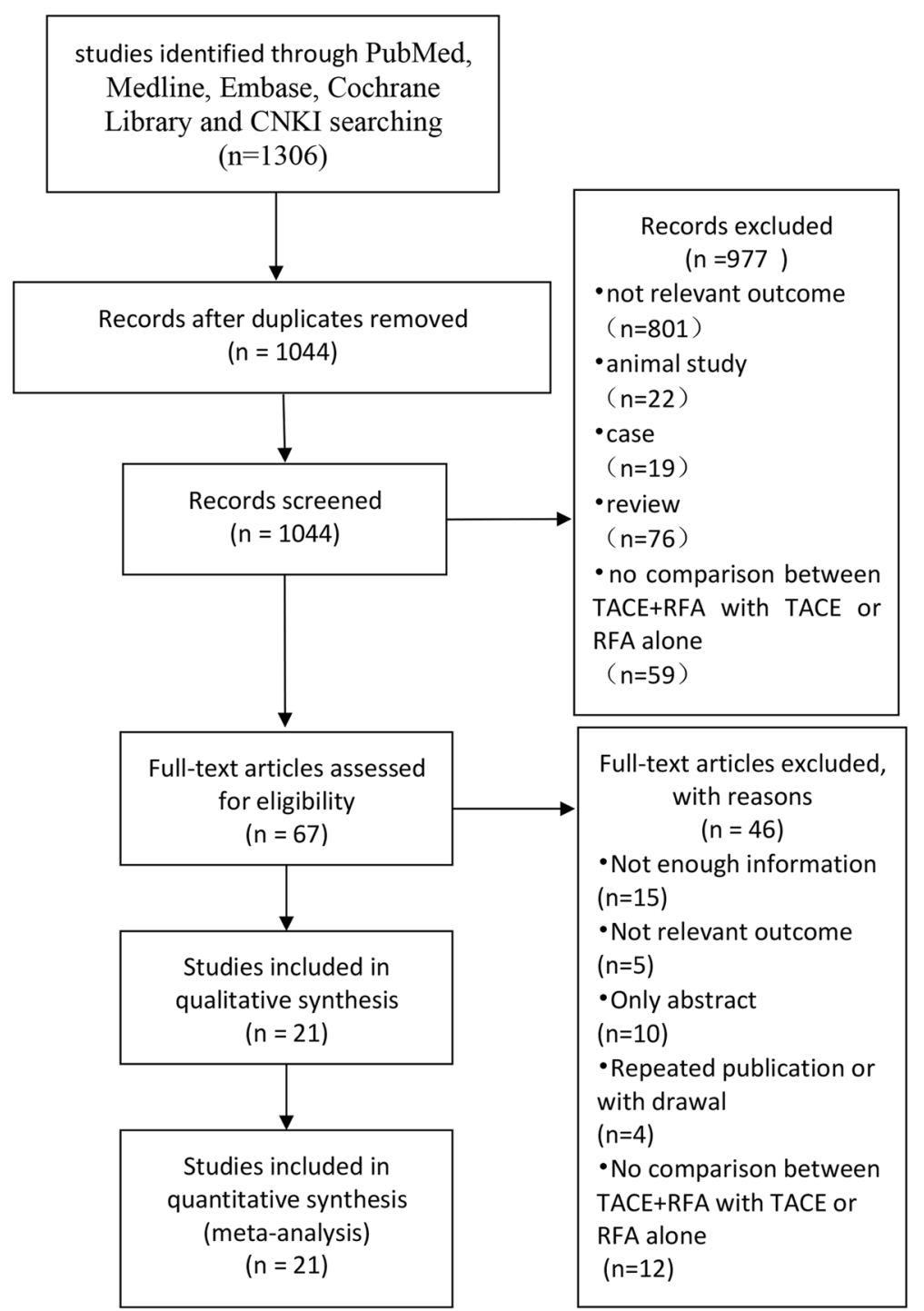

Fig. 1 The flow chart represents the screening process

Nine studies with 1273 patients reported the RFS for TACE+RFA vs RFA alone $\left(p=0.63, I^{2}=0 \%\right)$. Pooled results showed that the combined treatment group achieved better RFS than the RFA alone group ( $\mathrm{HR}=0.60,95 \% \mathrm{CI}$ $=0.51-0.71, p<0.001)$ (Fig. 2d) (Supplementary Table 3).

\section{Major complications}

A total of nineteen studies reported major complications (Supplementary Table 5A). Overall, the rates of major complications in the TACE combined with RFA group, the TACE group, and the RFA group were 2.71\% (35/ 1291), $1.55 \%$ (20/1292), and 1.71\% (12/701), respectively. The most observed major complications were gastrointestinal bleeding, abscess, liver failure, hepatic infarction, etc. (Supplementary Table 5B).
Fourteen studies with 2272 patients provided 49 major complications cases after TACE+RFA or TACE alone. The incidence of moderate to severe adverse effects for combined treatment was $2.96 \%$ (29/980), compared with only $1.55 \%(20 / 1292)$ in TACE monotherapy (OR $=1.78$, 95\% CI $=0.99-3.20, p=0.05$ ) (Fig. 3a) (Supplementary Table 4). Another group of nine studies, 1279 patients included, revealed similar rates of major complications of TACE+RFA vs RFA $(1.73 \%(10 / 578)$ vs $1.71 \%(12 /$ 701)) $(\mathrm{OR}=1.00,95 \% \mathrm{CI}=0.42-2.38, p=1.00)$ (Fig. 3b) (Supplementary Table 4) (Supplementary Table 5A).

\section{Subgroup analysis}

Subgroup of tumors of diameter $\leq 3 \mathrm{~cm}$

This subgroup results show that the combined treatment significantly improved OS and RFS (OS: $\mathrm{HR}=0.57,95 \%$ 
Table 1 The basic characteristics included in this meta-analysis

\begin{tabular}{|c|c|c|c|c|c|c|c|c|c|c|c|}
\hline Study & Country & Type & $\begin{array}{l}\text { Study } \\
\text { arms }\end{array}$ & NP & Age & $\begin{array}{l}\text { Gender } \\
\text { (M/F) }\end{array}$ & $\begin{array}{l}\text { Tumor size } \\
(\mathrm{cm})\end{array}$ & $\begin{array}{l}\text { Child-Pugh(A/ } \\
\text { B/C) }\end{array}$ & $\mathrm{HBsAg}+$ & $\begin{array}{l}\mathrm{HCV}- \\
\mathrm{Ab}+\end{array}$ & $\begin{array}{l}\text { NOS } \\
\text { score }\end{array}$ \\
\hline \multirow[t]{2}{*}{$\begin{array}{l}\text { Shibata et al. } \\
\text { [15] }\end{array}$} & \multirow[t]{2}{*}{ Japan } & \multirow[t]{2}{*}{$\begin{array}{l}\text { Cohort } \\
\text { study }\end{array}$} & TACE+RFA & 46 & $67.2 \pm 8.9$ & $31 / 15$ & $\begin{array}{l}1.7 \pm 0.6(0.9- \\
3.0)\end{array}$ & $32 / 14 / 0$ & 12 & 32 & \multirow[t]{2}{*}{$* * * * * * * * *$} \\
\hline & & & RFA & 43 & $69.8 \pm 8.0$ & $33 / 10$ & $\begin{array}{l}1.6 \pm 0.5(0.8- \\
2.6)\end{array}$ & $33 / 10 / 0$ & 9 & 30 & \\
\hline \multirow[t]{3}{*}{ Yang et al. [36] } & \multirow[t]{3}{*}{ China } & \multirow{3}{*}{$\begin{array}{l}\text { Cohort } \\
\text { study }\end{array}$} & TACE+RFA & 31 & $57.8(43.0-78.0)$ & $24 / 7$ & 3.5 & 20/10/1 & NA & NA & \multirow[t]{3}{*}{$* * * * * * * *$} \\
\hline & & & TACE & 35 & $51.2(30.0-74.0)$ & $30 / 5$ & 3.6 & 21/13/1 & NA & NA & \\
\hline & & & RFA & 37 & $58.3(38.0-80.0)$ & $27 / 10$ & 3.8 & 23/13/1 & NA & NA & \\
\hline \multirow{2}{*}{$\begin{array}{l}\text { Morimoto et al. } \\
\text { [37] }\end{array}$} & \multirow[t]{2}{*}{ Japan } & \multirow[t]{2}{*}{ RCT } & TACE+RFA & 19 & $70.0(57.0-78.0)$ & $15 / 4$ & $3.6 \pm 0.7$ & $18 / 1 / 0$ & 0 & 17 & \multirow[t]{2}{*}{-} \\
\hline & & & RFA & 18 & $73.0(48.0-84.0)$ & $12 / 6$ & $3.7 \pm 0.6$ & $16 / 2 / 0$ & 0 & 16 & \\
\hline \multirow[t]{2}{*}{ Kim et al. [16] } & \multirow{2}{*}{$\begin{array}{l}\text { South } \\
\text { Korea }\end{array}$} & \multirow{2}{*}{$\begin{array}{l}\text { Cohort } \\
\text { study }\end{array}$} & TACE+RFA & 83 & $59.7 \pm 10.4$ & $69 / 14$ & $2.5 \pm 0.3$ & $67 / 16 / 0$ & 50 & 11 & \multirow[t]{2}{*}{$* * * * * * * *$} \\
\hline & & & RFA & 231 & $58.0 \pm 10.1$ & $182 / 49$ & $2.4 \pm 0.3$ & $170 / 61 / 0$ & 158 & 19 & \\
\hline \multirow[t]{2}{*}{ Peng et al. [38] } & \multirow[t]{2}{*}{ China } & \multirow[t]{2}{*}{ RCT } & TACE+RFA & 69 & $\begin{array}{l}57.5 \pm 10.0(19.0- \\
75.0)\end{array}$ & $59 / 9$ & NA & $60 / 9 / 0$ & 63 & NA & \multirow[t]{2}{*}{-} \\
\hline & & & RFA & 70 & $\begin{array}{l}55.1 \pm 9.5(22.0- \\
75.0)\end{array}$ & $55 / 15$ & NA & $59 / 11 / 0$ & 65 & NA & \\
\hline \multirow[t]{2}{*}{ Lin et al. [39] } & \multirow[t]{2}{*}{ China } & \multirow{2}{*}{$\begin{array}{l}\text { Cohort } \\
\text { study }\end{array}$} & $\mathrm{TACE}+\mathrm{RFA}$ & 32 & $64.9 \pm 8.8$ & $24 / 8$ & $4.09 \pm 0.55$ & NA & NA & NA & $* * * * * * *$ \\
\hline & & & RFA & 30 & $60.1 \pm 10.2$ & $23 / 7$ & $3.94 \pm 0.54$ & NA & NA & NA & \\
\hline Peng et al. [40] & China & RCT & $\mathrm{TACE}+\mathrm{RFA}$ & 94 & $53.3 \pm 11$ & $75 / 19$ & $3.47 \pm 1.44$ & $90 / 4 / 0$ & 85 & 6 & - \\
\hline & & & RFA & 95 & $55.3 \pm 13.3$ & $71 / 24$ & $3.39 \pm 1.35$ & $90 / 5 / 0$ & 83 & 6 & \\
\hline Liu et al. [41] & China & Cohort & TACE+RFA & 45 & $45.0-75.0$ & $36 / 9$ & $4.0-15.0$ & $13 / 20 / 12$ & NA & NA & $* * * * * * *$ \\
\hline & & & TACE & 43 & $44.0-78.0$ & $34 / 9$ & $5.0-14.0$ & $10 / 23 / 10$ & NA & NA & \\
\hline Yin et al. [42] & China & & TACE+RFA & 55 & NA & $47 / 8$ & $5.9(5.0-8.0)$ & $48 / 7 / 0$ & 36 & NA & $* * * * * * * *$ \\
\hline & & & TACE & 156 & NA & $138 / 18$ & $6.0(5.0-8.0)$ & $136 / 20 / 0$ & 118 & NA & \\
\hline Gao et al. [43] & China & Cohort & TACE+RFA & 35 & $48.6 \pm 10.4$ & $31 / 4$ & $6.48 \pm 1.25$ & $24 / 11 / 0$ & 27 & NA & $* * * * * * * *$ \\
\hline & & & TACE & 32 & $51.8 \pm 11.0$ & $29 / 3$ & $7.05 \pm 1.47$ & $25 / 7 / 0$ & 26 & NA & \\
\hline Hyun et al. [44] & Korea & Cohort & TACE+RFA & 37 & $57.7 \pm 7.7$ & $31 / 6$ & NA & $34 / 3 / 0$ & 30 & 1 & $* * * * * * * *$ \\
\hline & & & TACE & 54 & $59.5 \pm 9.5$ & $42 / 12$ & NA & $45 / 9 / 0$ & 45 & 6 & \\
\hline Shi et al. [45] & China & Cohort & TACE+RFA & 31 & $64.0(39.0-48.0)$ & $24 / 7$ & NA & $29 / 2 / 0$ & NA & NA & $* * * * * * * *$ \\
\hline & & & TACE & 43 & $64.0(39.0-48.0)$ & $34 / 9$ & NA & $39 / 4 / 0$ & NA & NA & \\
\hline Song et al. [46] & Korea & Cohort & TACE+RFA & 87 & $60.4(29.1-78.0)$ & $70 / 17$ & $2.5(1.0-4.6)$ & $80 / 7 / 0$ & 58 & 21 & $* * * * * * * *$ \\
\hline & & & TACE & 71 & $60.0(23.0-87.2)$ & $53 / 18$ & $2.5(1.0-4.7)$ & $68 / 3 / 0$ & 49 & 14 & \\
\hline & & & RFA & 43 & $62.0(35.0-88.0)$ & $31 / 12$ & $2.2(1.3-4.7)$ & $37 / 6 / 0$ & 28 & 9 & \\
\hline Tang et al. [47] & China & Cohort & TACE+RFA & 40 & $48.28 \pm 13.48$ & 29/11 & $5.35 \pm 1.10$ & 18/22/0 & 16 & 9 & $* * * * * * * *$ \\
\hline & & & TACE & 43 & $45.84 \pm 15.08$ & $33 / 10$ & $5.64 \pm 1.41$ & 19/24/0 & 23 & 7 & \\
\hline & & & RFA & 49 & $47.14 \pm 13.27$ & $34 / 15$ & $5.78 \pm 1.35$ & $22 / 27 / 0$ & 26 & 12 & \\
\hline Kim et al. [48] & Korea & Cohort & TACE+RFA & 105 & $63.4 \pm 9.7$ & $82 / 23$ & $2.83 \pm 0.76$ & $98 / 7 / 0$ & 71 & 17 & $* * * * * * * * *$ \\
\hline & & & TACE & 102 & $62.4 \pm 10.2$ & $81 / 21$ & $2.87 \pm 0.92$ & $82 / 20 / 0$ & 60 & 20 & \\
\hline Zhu et al. [49] & China & Cohort & TACE+RFA & 35 & $47.5 \pm 10.3$ & $26 / 9$ & $5.97 \pm 1.28$ & $24 / 11 / 0$ & NA & NA & $* * * * * * * *$ \\
\hline & & & TACE & 37 & $48.1 \pm 10.8$ & $29 / 8$ & $6.02 \pm 1.31$ & $28 / 9 / 0$ & NA & NA & \\
\hline Shimose et al. & Japan & Cohort & TACE+RFA & 68 & $70.5(46-89)$ & $26 / 42$ & $3.27(2.1-5.8)$ & NA & 4 & 57 & $* * * * * * * *$ \\
\hline & & & TACE & 68 & $71(48-85)$ & $27 / 41$ & $3.14(1.0-8.5)$ & NA & 10 & 50 & \\
\hline Liu et al. [51] & China & $\begin{array}{l}\text { Cohort } \\
\text { study }\end{array}$ & TACE+RFA & 209 & $\begin{array}{l}59.2 \pm 4.0(18- \\
75)\end{array}$ & $184 / 25$ & NA & 189/20/0 & 180 & 10 & $* * * * * * * *$ \\
\hline & & & TACE & 195 & $\begin{array}{l}58.7 \pm 4.0(20- \\
75)\end{array}$ & $165 / 30$ & NA & $180 / 15 / 0$ & 176 & 7 & \\
\hline Lee et al. [52] & Korea & Cohort & $\mathrm{TACE}+\mathrm{RFA}$ & 82 & $60.3 \pm 10.6$ & $60 / 22$ & $1.77 \pm 0.60$ & $77 / 5 / 0$ & 58 & 15 & $* * * * * * * *$ \\
\hline
\end{tabular}


Table 1 The basic characteristics included in this meta-analysis (Continued)

\begin{tabular}{|c|c|c|c|c|c|c|c|c|c|c|c|}
\hline Study & Country & Type & $\begin{array}{l}\text { Study } \\
\text { arms }\end{array}$ & NP & Age & $\begin{array}{l}\text { Gender } \\
(\mathrm{M} / \mathrm{F})\end{array}$ & $\begin{array}{l}\text { Tumor size } \\
(\mathrm{cm})\end{array}$ & $\begin{array}{l}\text { Child-Pugh(A/ } \\
\mathrm{B} / \mathrm{C})\end{array}$ & HBsAg+ & $\begin{array}{l}\text { HCV- } \\
\mathrm{Ab}+\end{array}$ & $\begin{array}{l}\text { NOS } \\
\text { score }\end{array}$ \\
\hline & & study & TACE & 85 & $60.6 \pm 10.3$ & $59 / 26$ & $1.91 \pm 0.62$ & $76 / 9 / 0$ & 64 & 5 & \\
\hline \multirow[t]{3}{*}{ Chu et al. [53] } & \multirow[t]{3}{*}{ Korea } & \multirow{3}{*}{$\begin{array}{l}\text { Cohort } \\
\text { study }\end{array}$} & TACE+RFA & 109 & $58.4 \pm 10.2$ & $83 / 26$ & $3.7 \pm 0.5$ & $93 / 16 / 0$ & 79 & 17 & \multirow[t]{3}{*}{$* * * * * * *$} \\
\hline & & & TACE & 314 & $60.5 \pm 10.6$ & $224 / 90$ & $3.8 \pm 0.5$ & $254 / 60 / 0$ & 221 & 40 & \\
\hline & & & RFA & 115 & $61.1 \pm 10.8$ & $90 / 25$ & $3.5 \pm 0.4$ & $83 / 32 / 0$ & 74 & 17 & \\
\hline \multirow[t]{2}{*}{ Endo et al. [54] } & \multirow[t]{2}{*}{ Japan } & \multirow{2}{*}{$\begin{array}{l}\text { Cohort } \\
\text { study }\end{array}$} & TACE+RFA & 46 & $74.0(46.0-87.0)$ & $35 / 11$ & $3.2(1.2-4.8)$ & $36 / 10 / 0$ & 5 & 27 & \multirow[t]{2}{*}{$* * * * * * *$} \\
\hline & & & TACE & 46 & $74.0(54.0-89.0)$ & $30 / 16$ & $3.4(1.1-4.9)$ & $31 / 15 / 0$ & 3 & 24 & \\
\hline
\end{tabular}

TACE transcatheter arterial chemoembolization, RFA radiofrequency ablation, NP number of patients, NA not applicable, M/F male/famale, $R C T$ randomized control trial, NOS Newcastle-Ottawa scale

Tabel 2 Subgroup analysis based on the tumor size and the age

$\mathrm{CI}=0.41-0.81, p=0.002 ; \quad \mathrm{RFS}: \mathrm{HR}=0.47,95 \% \mathrm{CI}=0.30$ $0.73, p<0.001)$ compared with TACE alone. However, the combined group did not have better OS and RFS than RFA alone. (OS: $\mathrm{HR}=0.77,95 \% \mathrm{CI}=0.55-1.09, p=$ 0.14; RFS: $\mathrm{HR}=0.82,95 \% \mathrm{CI}=0.57-1.19, p=0.30)$ alone (Table 2) (Supplementary Figure 3).

\section{Subgroup of tumors of diameter $>3 \mathrm{~cm}$}

Meta-analysis of comparing TACE+RFA with TACE or RFA alone for tumors diameter larger than $3 \mathrm{~cm}$ showed that the combined group have better OS and RFS than TACE (OS: $\mathrm{HR}=0.61,95 \% \mathrm{CI}=0.52-0.73, p<0.001$; RFS: $\mathrm{HR}=0.56,95 \% \mathrm{CI}=0.35-0.89, p=0.01)$ or RFA (OS: HR= 0.61, 95\% CI $=0.49-0.76, p<0.001$; RFS: HR $=0.55,95 \%$ $\mathrm{CI}=0.45-0.67, p<0.001$ ) alone (Table 2) (Supplementary Figure 3).

\section{Subgroup of age $<60$}

Meta-analysis of comparing TACE+RFA with TACE or RFA alone for age $<60$ showed that the combined group have better OS and RFS than TACE (OS: HR $=0.61,95 \%$ $\mathrm{CI}=0.51-0.73, p<0.001$; RFS: $\mathrm{HR}=0.51,95 \% \mathrm{CI}=0.30$ $0.87, p=0.01$ ) or RFA (OS: $\mathrm{HR}=0.61,95 \% \mathrm{CI}=0.49-0.77$, $p<0.001$; RFS: $\mathrm{HR}=0.55,95 \% \mathrm{CI}=0.43-0.70, \underline{p}<0.001)$ alone (Table 2) (Supplementary Figure 4).

\section{Subgroup of age $\geq 60$}

Meta-analysis of comparing TACE+RFA with TACE alone for age $\geq 60$ shows that the combined treatment significantly improved OS and RFS (OS: HR $=0.58,95 \%$ $\mathrm{CI}=0.46-0.74, p<0.001$; RFS: $\mathrm{HR}=0.46,95 \% \mathrm{CI}=0.36-$ $0.57, p<0.001)$ compared with TACE alone. However, the combined group has similar OS and RFS as RFA alone (OS: HR=0.72, 95\% CI $=0.49-1.04, p=0.08$; RFS: $\mathrm{HR}=0.80,95 \% \mathrm{CI}=0.58-1.11, p=0.19)$ alone (Table 2) (Supplementary Figure 4).

\section{Publication bias and sensitivity analysis}

Funnel plots, Begg's test, and Egger's test were used to assess potential publication bias in this meta-analysis. The four funnel plots were roughly symmetrical on both sides (Fig. 4). In the group of TACE+RFA vs TACE, the studies yielded a Begg's test score of $p=0.727$ and an Egger's test score of $p=0.143$, and similar results were found for RFS ( $p=0.260$ and 0.109 , respectively); in the group of TACE+RFA vs RFA, the studies yielded a Begg's test score of $p=1.000$ and an Egger's test score of $p=0.438$, similar results were found for RFS $(p=0.118$ and 0.073 , respectively), and so it can be considered that there was little publication bias in this meta-analysis.

Sensitivity analysis was performed by excluding individual studies to assess the impact of single studies on the stability of the combined results (Fig. 5), and we found that the combined results did not change after excluding any study. Therefore, the pooled results of this meta-analysis have been shown to be stable.

\section{Discussion}

TACE and RFA are widely used in the treatment of HCC, but their application is controversial due to their corresponding deficiencies. In theory, the combination could improve treatment outcomes. TACE is usually recommended as the first choice for treatment of patients with BCLC Intermediate Stage (Stage B) disease that is inoperable. As a bridge treatment, some patients have the opportunity to undergo liver resection, RFA, or liver transplantation following TACE $[55,56]$. Normal liver tissue has a double blood supply, both arterial and venous. However, HCC tissue is mainly supplied by arteries. In TACE, the chemotherapeutic drugs and embolization agents block the tumor blood supply, leading to tumor ischemia and hypoxia, which can inhibit tumor growth and promote tumor necrosis and apoptosis. However, hypoxia following embolization can stimulate the release of vascular endothelial growth factor (VEGF), which promotes the formation of new blood vessels in tumor areas [57-59]. Therefore, local recurrence is the main type after TACE treatment [60]. The RFA technique leads to coagulation necrosis in tumor tissue through heat, killing tumor cells. However, it is not only necessary to destroy tumor tissue, but also to ablate more than $1 \mathrm{~cm}$ of tissue at the edge of the 


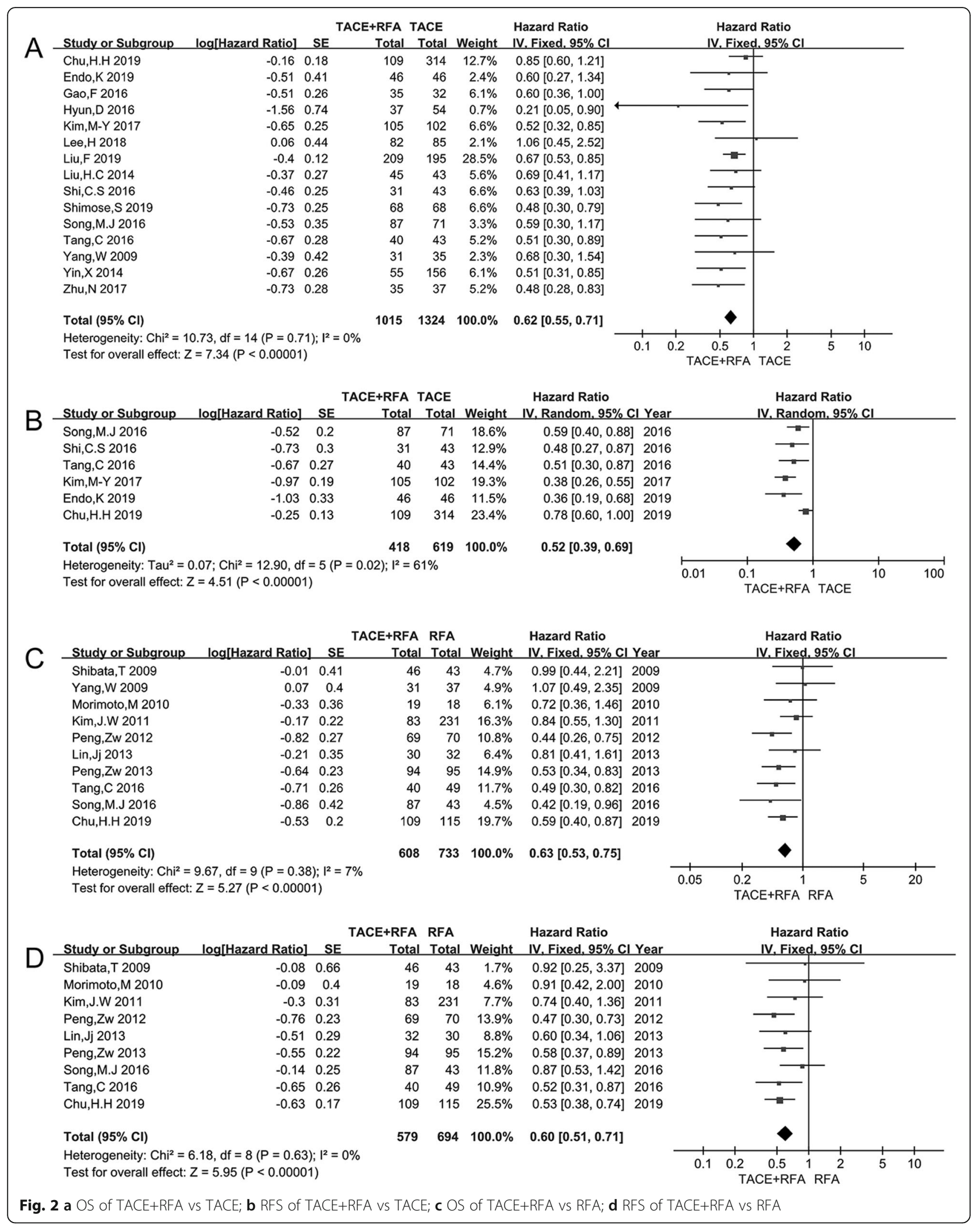




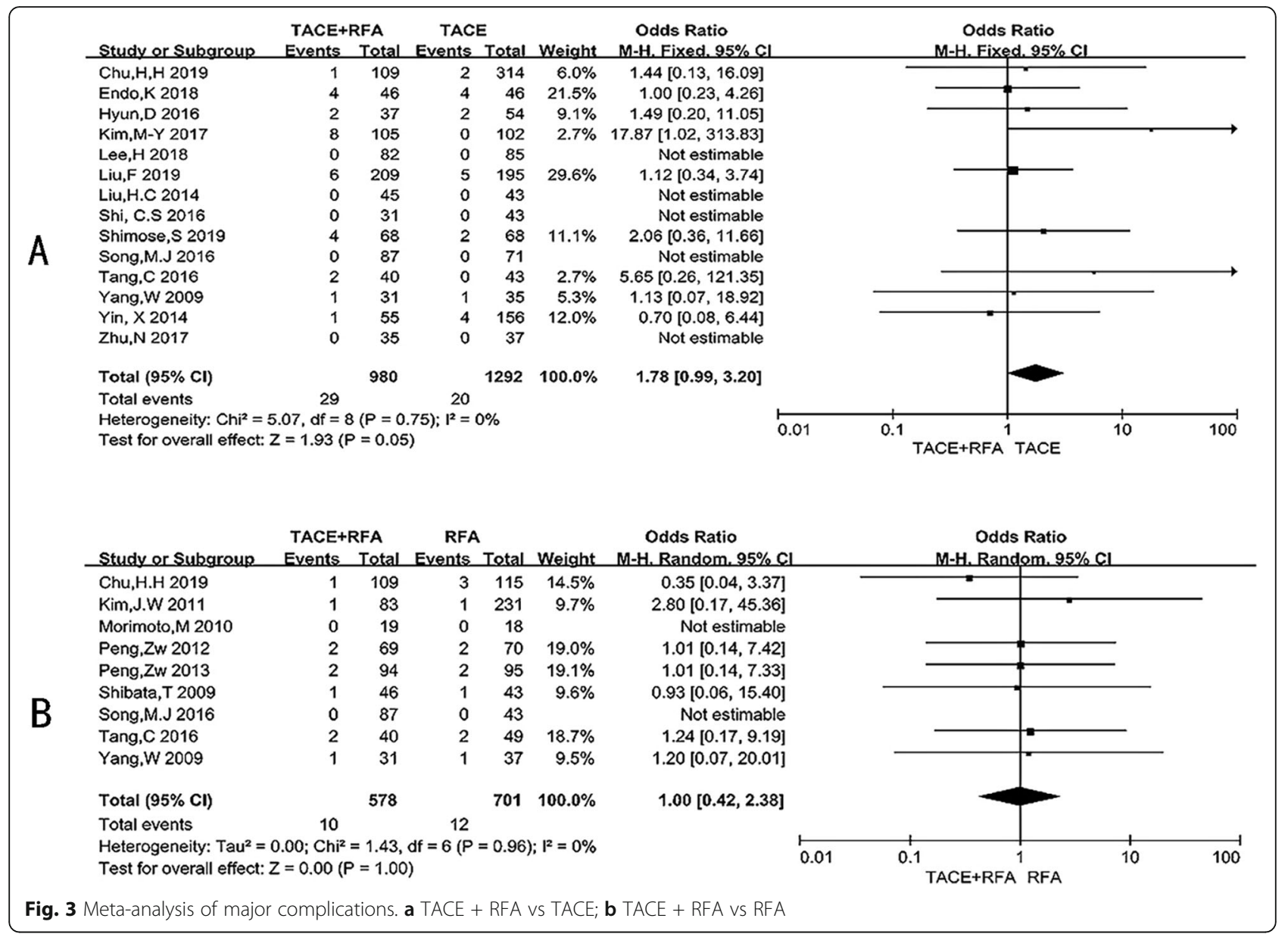

tumor, so as to eliminate microsatellite foci and prevent recurrence [61]. Studies have shown that in cases of tumors larger than $3 \mathrm{~cm}$ with incomplete ablation, the risk of local recurrence is increased [62]. The heat-sink effect may be a reason for incomplete RFA ablation. The rich blood supply to the tumor tissue takes away the heat, thus reducing the therapeutic effect of RFA [63].

The use of TACE prior to RFA can block the blood supply of the tumor, minimize the heat loss caused by

Table 2 Subgroup analysis based on the tumor size and the age

\begin{tabular}{|c|c|c|c|c|c|c|c|c|c|c|}
\hline \multirow[t]{2}{*}{ Criteria } & \multicolumn{5}{|l|}{ os } & \multicolumn{5}{|l|}{ RFS } \\
\hline & NO. of studies & NP & HR $(95 \% \mathrm{Cl})$ & $1^{2}$ & $p$ value $Q$ test & No. of studies & NP & HR (95\% Cl) & $I^{2}$ & $p$ value $Q$ test \\
\hline \multicolumn{11}{|c|}{ TACE+RFA vs. TACE } \\
\hline$\leq 3 \mathrm{~cm}$ & 4 & 623 & $0.57(0.41-0.81)$ & $24 \%$ & 0.27 & 2 & 365 & $0.47(0.30-0.73)$ & $62 \%$ & 0.10 \\
\hline$>3 \mathrm{~cm}$ & 9 & 1238 & $0.61(0.52-0.73)$ & $0 \%$ & 0.63 & 3 & 598 & $0.56(0.35-0.89)$ & $67 \%$ & 0.05 \\
\hline Age $<60$ & 6 & 783 & $0.61(0.51-0.73)$ & $0 \%$ & 0.57 & 1 & 83 & $0.51(0.30-0.87)$ & NA & NA \\
\hline Age $\geq 60$ & 6 & 834 & $0.58(0.46-0.74)$ & $0 \%$ & 0.74 & 4 & 531 & $0.46(0.36-0.57)$ & $9 \%$ & 0.35 \\
\hline \multicolumn{11}{|c|}{ TACE+RFA vs. RFA } \\
\hline$\leq 3 \mathrm{~cm}$ & 3 & 533 & $0.77(0.55-1.09)$ & $22 \%$ & 0.28 & 3 & 533 & $0.82(0.57-1.19)$ & $0 \%$ & 0.91 \\
\hline$>3 \mathrm{~cm}$ & 6 & 669 & $0.61(0.49-0.76)$ & $0 \%$ & 0.54 & 5 & 678 & $0.55(0.45-0.67)$ & $0 \%$ & 0.47 \\
\hline Age $<60$ & 5 & 799 & $0.61(0.49-0.77)$ & $41 \%$ & 0.15 & 4 & 731 & $0.55(0.43-0.70)$ & $0 \%$ & 0.68 \\
\hline Age $\geq 60$ & 4 & 318 & $0.72(0.49-1.04)$ & $0 \%$ & 0.51 & 4 & 318 & $0.80(0.58-1.11)$ & $0 \%$ & 0.63 \\
\hline
\end{tabular}

TACE transcatheter arterial chemoembolization, RFA radiofrequency ablation, NP number of patients, NA not applicable, HR hazard ratio, OS overall survival, RFS recurrence-free survival 


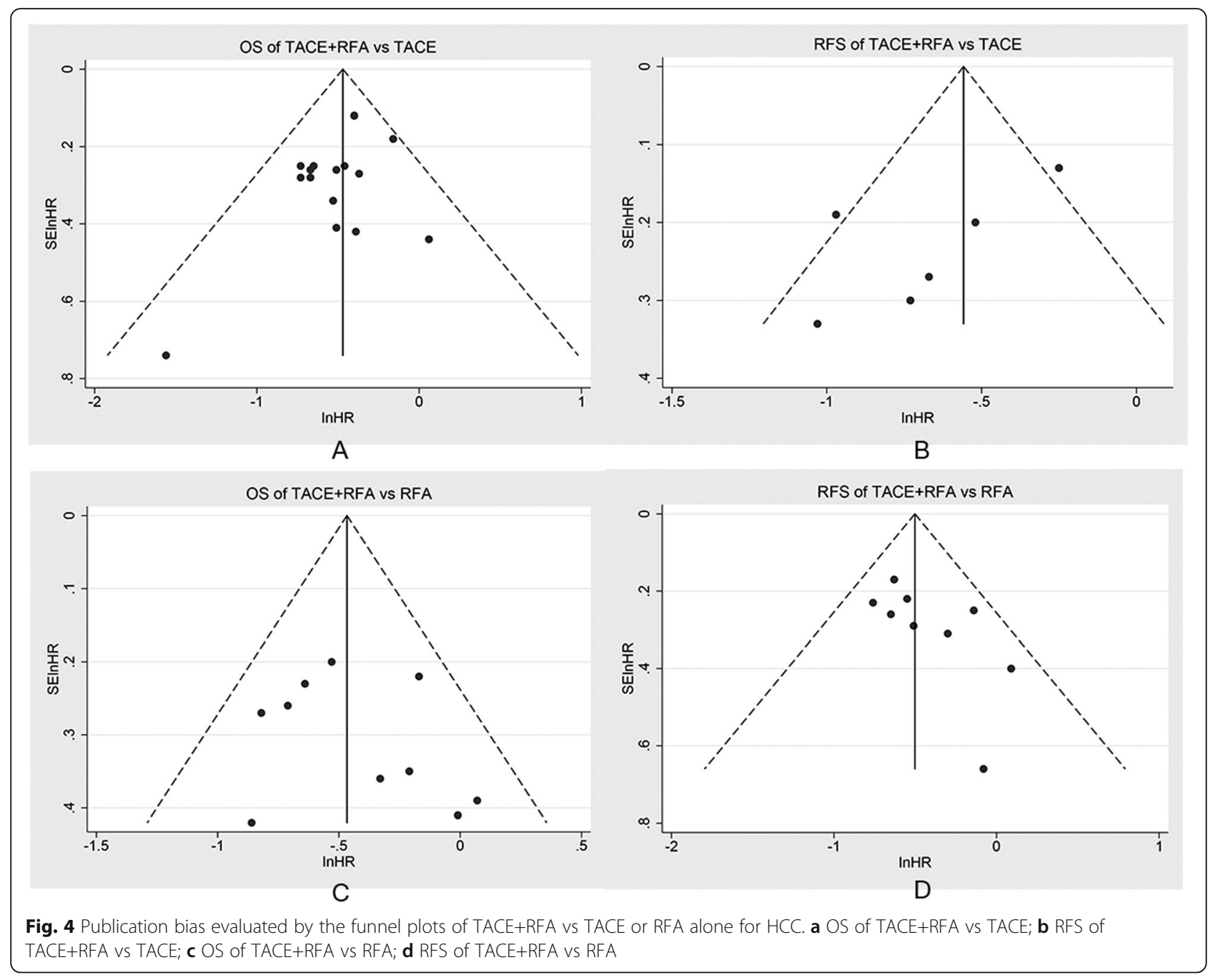

the heat-sink effect, increase the area of coagulation necrosis, produce more thorough internal necrosis of the mass, and expand the edge of the ablation to destroy the satellite lesions $[15,64,65]$. TACE is generally suitable for highly vascularized liver cancer, and this tumor property will increase the heat-sink effect of RFA therapy. Therefore, combined use has significant advantages [66]. In addition, as a regional treatment, TACE can identify satellite lesions missed by imaging, thus providing a target for subsequent RFA treatment [47]. At the same time, RFA treatment after TACE can kill tumor additional cells, destroy new blood vessels, and reduce tumor recurrence. Previous studies have shown that RFA can increase the deposition of some chemotherapeutic agents [67]. The research of Ako et al. shows that RFA treatment can achieve better clinical benefit at 720 days after TACE [68]. Such evidence shows that TACE combined with RFA in the treatment of HCC, especially in larger than $3 \mathrm{~cm}$ tumor, can reduce the recurrence rate and prolong the survival time.
So far, there have been some meta-analyses. Wang et al. [69] reported the meta-analysis comparing OS for patients receiving TACE+RFA and RFA alone in HCC. They analyzed six studies with 534 patients and showed similar OS and RFS. Yang et al. [21] investigated the outcome of TACE+RFA compared to TACE alone in HCC patients. They showed a survival benefit for combined therapy compared to TACE alone $\left(\mathrm{OR}_{1 \text {-year }}=\right.$ 3.92, $95 \% \mathrm{CI}=2.41-6.39, p<0.00001 ; \mathrm{OR}_{3 \text {-year }}=2.56$; $95 \% \mathrm{CI}=1.81-3.60 ; p<0.00001 ; \mathrm{OR}_{5 \text {-year }}=2.78,95 \% \mathrm{CI}=$ $1.77-4.38 ; p<0.0001)$. However, previous meta-analyses only compared the efficacy of combination therapy versus either TACE or RFA, instead of making comparisons together. And a number of high-quality studies have been published in recent years; in addition, our study removed studies that were included in previous metaanalyses but were judged to be of low quality. As we know, our study is the largest meta-analysis including high-quality research through reasonable quality evaluation and subgroup analysis with clinical significance. 


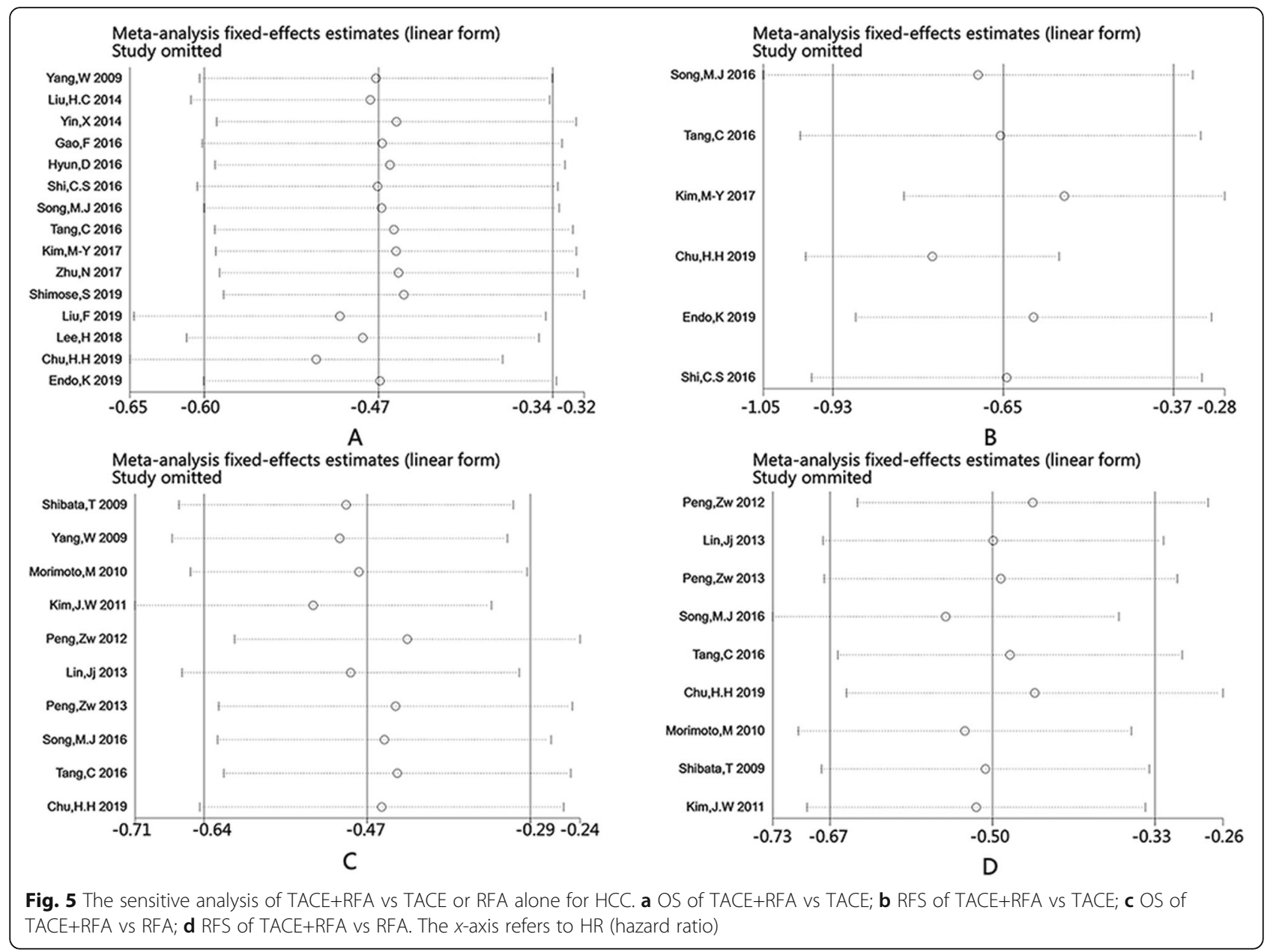

The result of this meta-analysis indicates that the OS and RFS rates of TACE combined with RFA are higher than those achieved with TACE alone $(\mathrm{HR}=0.62,95 \%$ CI: $0.55-0.71, p<0.001$; HR=0.52, 95\% CI=0.39-0.69, $p<$ 0.001 , respectively). The subgroup analysis results were the same as the overall results. The specific analysis also showed that although there was no significant difference of complications between the combined treatment group and the mono-therapy group, and the overall adverse events were prominent phenomena for patients who received associated therapies. This meta-analysis showed that TACE+RFA was better than RFA alone in the treatment of HCC in terms of both OS and RFS (HR $=0.63$, 95\% CI: $0.53-0.75, p<0.001 ; \mathrm{HR}=0.60,95 \% \mathrm{CI}=0.51-$ $0.71, p<0.001$, respectively), but in a subgroup of age $\geq 60$ and tumors diameter $\leq 3 \mathrm{~cm}$, there was no significant difference in OS and RFS between the combined group and the RFA alone group, so maybe RFA treatment is enough for these patients, but further research is needed to support this conclusion. In order to find the source of heterogeneity and eliminate it, we have performed a descriptive statistics analysis of clinicopathological characteristics of patients in 21 included studies (Supplementary Table 2) and found that some differences, such as country, tumor size, and Child-Pugh classification, which may be caused by different sources and inclusion criteria of various studies; these can be the sources of heterogeneity. Therefore, we selected the indicators that may have an impact on the prognosis for subgroup analysis. Then, we divided the studies into subgroups based on age and tumor size, and heterogeneity remained in subgroups based on tumor size, but decreased significantly in subgroups based on age; so, we hypothesized that heterogeneity might be due to the age of patients enrolled in different studies. Therefore, the results may need to be treated with caution.

Previous research reported that there was no significant difference in major complications between the combined treatment group and the RFA alone group [21]. The current meta-analysis shows a similar outcome 
$(\mathrm{OR}=1.00,95 \% \mathrm{CI}=0.42-2.38, p=1.00)$. Regarding major complications of TACE+RFA vs TACE, this metaanalysis also shows similar pooled outcomes $(\mathrm{OR}=1.78$, 95\% CI: $0.99-3.20, p=0.05)$ as another study [69]. Two patients died of hemorrhagic shock and liver failure, respectively, in the combined group and the TACE alone group $[16,36]$. Although local treatment can result in a maximal reduction of systemic adverse reactions and trauma, fever, abdominal pain, fatigue, bone marrow depression, and other systemic manifestations are still common complications. Procedural safety is evaluated by the occurrence of serious complications, which is obviously not a comprehensive measure. Moreover, the definitions of severe complications are different in each study.

In a previously published meta-analysis, it was reported to be controversial to evaluate OS and RFS with ORs such as 1 year, 3 years, and 5 years [21]. Firstly, OR only describes information at a certain time point, so it cannot describe the entire process well. Next, the follow-up time was inconsistent in the original studies, which aggravated the occurrence of heterogeneity. In this study, HR was used to evaluate the time-to-event outcomes. In addition, some previous research did not use reasonable methods to evaluate the quality of literature [70]. In the present meta-analysis, the risk of bias was used to evaluate RCTs, and the NOS scale was used to evaluate cohort studies. As much as possible, research of higher quality was incorporated to evaluate TACE combined with RFA for the treatment of HCC. This meta-analysis use HR to assess the prognosis and safety of TACE+RFA and TACE or RFA alone in the treatment of HCC.

The present meta-analysis has some limitations. Firstly, although twenty-one studies were included, there were only three RCTs, so the quality of the evidence was relatively low. Secondly, all participants in the original studies were Asian, and eleven of these studies were conducted in China. Because HCC in China is often associated with hepatitis B (HBV), in contrast to the prevalence of $\mathrm{HCV}$ infection in Western countries, the results of this meta-analysis may not be applicable to other populations. Even in Asian countries, there was some heterogeneity in clinicopathological characteristics of patients such as Child-Pugh classification, tumor size, nationality, etc. due to different inclusion criteria and sources among studies. Owing to the lack of sufficient information in the original research, this meta-analysis was unable to include evaluation on the basis of different tumor stages. Lastly, owing to the small number of original studies in the subgroup analysis, the credibility of the results may be questionable. Therefore, additional high-quality RCTs and studies in other ethnic groups are needed to further explore TACE combined with RFA in the treatment of HCC.

\section{Conclusion}

TACE combined with RFA might achieve better outcome for HCC patients compared with applied individually; moreover, the incidence of major complications with combined treatment was not increased compared to that with treatment alone, but we need further clinical trials to provide more evidence for this treatment attempt.

\section{Abbreviations}

TACE: Transcatheter arterial chemoembolization; RFA: Radiofrequency ablation; HCC: Hepatocellular carcinoma; CNKI: China National Knowledge Infrastructure; OS: Overall survival; RFS: Recurrence-free survival; HR: Hazard ratio; Cl: Confidence intervals; RCTs: Randomized controlled trials; NOS: Newcastle Ottawa Quality Assessment Scale; OR: Odds ratio; VEGF: Vascular endothelial growth factor

\section{Supplementary Information}

The online version contains supplementary material available at https://doi. org/10.1186/s12957-021-02188-4.

Additional file 1: Supplementary Figure 1. The necessary steps of the methodology.

Additional file 2: Supplementary Figure 2. Risk of bias assessment of included RCTs.

Additional file 3: Supplementary Figure 3. The subgroup analysis of TACE+RFA vs TACE or RFA alone for HCC based on the tumor size. (A) TACE+RFA vs TACE:OS;(B)TACE+RFA vs TACE:RFS;(C)TACE+RFA vs RFA:OS;(D)TACE+RFA vS RFA:RFS.

Additional file 4: Supplementary Figure 4. The subgroup analysis of TACE+RFA vs TACE or RFA alone for HCC based on age. (A) TACE+RFA vs TACE:OS;(B)TACE+RFA vs TACE:RFS;(C)TACE+RFA vs RFA:OS;(D)TACE+RFA vs RFA: RFS.

Additional file 5: Supplementary Table 1. The NOS quality assessment of included cohort studies.

Additional file 6: Supplementary Table 2. Clinicopathological characteristics of patients in included studies.

Additional file 7: Supplementary Table 3. The OS and RFS of TACE+RFA vs TACE or RFA.

Additional file 8: Supplementary Table 4. The comparison of major complication of TACE+RFA vs TACE or RFA.

Additional file 9: Supplementary Table 5A. Major complications reported among the included studies.

Additional file 10: Supplementary Table 5B. Details of Major Complications among Included Studies.

Acknowledgements

Not applicable.

\section{Authors' contributions}

CJ, MHL: Study concept and design; CJ, GC: Acquisition of data; CJ, MHL: Analysis and interpretation; CJ: Draft the manuscript and preliminary revise; JWH: Study supervision and final approval. The authors read and approved the final manuscript.

\section{Funding}

Not applicable.

Availability of data and materials

All the data analyzed in this study are obtained from the original articles. 


\section{Declarations}

Ethics approval and consent to participate

Not applicable.

\section{Consent for publication}

Not applicable.

\section{Competing interests}

The authors declare that they have no competing interests.

\section{Author details}

'Department of Liver Surgery, Liver Transplantation Center, West China Hospital, Sichuan University, Chengdu, Sichuan, China. ${ }^{2}$ Department of Gastroenterology, Cadre Ward, Gansu Provincial Hospital, lanzhou, Gansu, China.

Received: 25 September 2020 Accepted: 3 December 2020 Published online: 19 March 2021

\section{References}

1. Forner A, Reig M, Bruix J, et al. Lancet. 2018;391:1301-14.

2. Bray F, Ferlay J, Soerjomataram I, Siegel RL, Torre LA, Jemal A. Global cancer statistics 2018: GLOBOCAN estimates of incidence and mortality worldwide for 36 cancers in 185 countries. CA Cancer J Clin. 2018:68:394-424.

3. Morgan TR, Mandayam S, Jamal MM. Alcohol and hepatocellular carcinoma. Gastroenterology. 2004;127(5):S87-96. https://doi.org/10.1053/j.gastro.2004. 09.020.

4. Kanwal F, Kramer JR, Duan Z, Yu X, White D, El-Serag HB. Trends in the burden of nonalcoholic fatty liver disease in a United States Cohort of Veterans. Clin Gastroenterol Hepatol. 2016;14:301-8.e1-2.

5. Forner A, Díaz-González A, Liccioni A, Vilana R. Prognosis prediction and staging. Best practice \& research. Clin Gastroenterol. 2014;28:855-65.

6. Yau T, Tang VY, Yao TJ, Fan ST, Lo CM, Poon RT. Development of Hong Kong Liver Cancer staging system with treatment stratification for patients with hepatocellular carcinoma. Gastroenterology. 2014:146:1691-700.e3.

7. Varshosaz J, Farzan M. Nanoparticles for targeted delivery of therapeutics and small interfering RNAs in hepatocellular carcinoma. World J Gastroenterol. 2015;21:12022-41.

8. Erstad DJ, Tanabe KK. Hepatocellular carcinoma: early-stage management challenges. J Hepatocell Carcinoma. 2017:4:81-92.

9. Lencioni R, Cioni D, Crocetti L, Franchini C, Pina CD, Lera J, Bartolozzi C. Early-stage hepatocellular carcinoma in patients with cirrhosis: long-term results of percutaneous image-guided radiofrequency ablation. Radiology. 2005;234(3):961-7. https://doi.org/10.1148/radiol.2343040350.

10. Omata M, Tateishi R, Yoshida H, Shiina S. Treatment of hepatocellular carcinoma by percutaneous tumor ablation methods: ethanol injection therapy and radiofrequency ablation. Gastroenterology. 2004;127(5):S159-66. https://doi.org/10.1053/j.gastro.2004.09.030.

11. Pompili M, Saviano A, de Matthaeis N, Cucchetti A, Ardito F, Federico B, et al. Long-term effectiveness of resection and radiofrequency ablation for single hepatocellular carcinoma $\leq 3 \mathrm{~cm}$. Results of a multicenter Italian survey. J Hepatol. 2013:59:89-97.

12. Huang J, Yan L, Cheng Z, Wu H, Du L, Wang J, et al. A randomized trial comparing radiofrequency ablation and surgical resection for HCC conforming to the Milan criteria. Ann Surg. 2010;252:903-12.

13. Lee BC, Lee HG, Park IJ, Kim SY, Kim KH, Lee JH, Kim CW, Lee JL, Yoon YS, Lim SB, Yu CS, Kim JC. The role of radiofrequency ablation for treatment of metachronous isolated hepatic metastasis from colorectal cancer. Medicine. 2016;95(39):e4999. https://doi.org/10.1097/MD.0000000000004999.

14. Doyon D, Mouzon A, Jourde AM, Regensberg C, Frileux C. Hepatic, arterial embolization in patients with malignant liver tumours (author's transl). Ann Radiol. 1974:17:593-603.

15. Shibata T, Isoda H, Hirokawa Y, Arizono S, Shimada K, Togashi K. Small hepatocellular carcinoma: is radiofrequency ablation combined with transcatheter arterial chemoembolization more effective than radiofrequency ablation alone for treatment? Radiology. 2009;252(3):905-13. https://doi.org/10.1148/radiol.2523081676.

16. Kim JW, Kim JH, Won HJ, Shin YM, Yoon HK, Sung KB, et al. Hepatocellular carcinomas $2-3 \mathrm{~cm}$ in diameter: transarterial chemoembolization plus radiofrequency ablation vs. radiofrequency ablation alone. Eur J Radiol. 2012;81:e189-93.

17. Becker G, Soezgen T, Olschewski M, Laubenberger J, Blum HE, Allgaier HP. Combined TACE and PEI for palliative treatment of unresectable hepatocellular carcinoma. World J Gastroenterol. 2005;11:6104-9.

18. Bartolozzi C, Lencioni R, Caramella D, Vignali C, Cioni R, Mazzeo S, Carrai M, Maltinti G, Capria A, Conte PF. Treatment of large HCC: transcatheter arterial chemoembolization combined with percutaneous ethanol injection versus repeated transcatheter arterial chemoembolization. Radiology. 1995;197(3): 812-8. https://doi.org/10.1148/radiology.197.3.7480761.

19. Liao M, Huang J, Zhang T, Wu H. Transarterial chemoembolization in combination with local therapies for hepatocellular carcinoma: a metaanalysis. Plos One. 2013:8:e68453.

20. Ni JY, Liu SS, Xu LF, Sun HL, Chen YT. Meta-analysis of radiofrequency ablation in combination with transarterial chemoembolization for hepatocellular carcinoma. World J Gastroenterol. 2013;19: 3872-82.

21. Yang DJ, Luo KL, Liu H, Cai B, Tao GQ, Su XF, Hou XJ, Ye F, Li XY, Tian ZQ. Meta-analysis of transcatheter arterial chemoembolization plus radiofrequency ablation versus transcatheter arterial chemoembolization alone for hepatocellular carcinoma. Oncotarget. 2017:8(2):2960-70. https:// doi.org/10.18632/oncotarget.13813.

22. Cao JH, Zhou J, Zhang XL, Ding X, Long QY. Meta-analysis on radiofrequency ablation in combination with transarterial chemoembolization for the treatment of hepatocellular carcinoma. J Huazhong Univ Sci Technol. 2014;34:692-700.

23. Liu Z, Gao F, Yang G, Singh S, Lu M, Zhang T, Zhong Z, Zhang F, Tang R. Combination of radiofrequency ablation with transarterial chemoembolization for hepatocellular carcinoma: an up-to-date metaanalysis. Tumour Biol. 2014;35(8):7407-13. https://doi.org/10.1007/s13277014-1976-Z.

24. Higgins JP, Altman DG, Gøtzsche PC, Jüni P, Moher D, Oxman AD, et al. The Cochrane Collaboration's tool for assessing risk of bias in randomised trials. BMJ. 2011;343:d5928.

25. Wells GA. The Newcastle-Ottawa Scale (NOS) for assessing the quality of nonrandomised studies in meta-analyses. Paper presented at: Symposium on Systematic Reviews: Beyond the Basics; 2000.

26. Julian Pt Higgins, Sally Green. Cochrane handbook for systematic reviews of interventions version 5.0.0. Naunyn-Schmiedebergs Archiv für experimentelle Pathologie und Pharmakologie.2008:5:S38.

27. Geiss K, Meyer M. Regional comparison of cancer incidence, mortality, and survival on the level of federal states in Germany using funnel plots. Eur J Cancer Prevent. 2019;28:234-42.

28. Sterne JA, Egger M. Funnel plots for detecting bias in meta-analysis: guidelines on choice of axis. J Clin Epidemiol. 2001;54:1046-55.

29. Sterne JA, Gavaghan D, Egger M. Publication and related bias in metaanalysis: power of statistical tests and prevalence in the literature. J Clin Epidemiol. 2000;53:1119-29.

30. Egger M, Smith GD, Schneider M, Minder C. Bias in meta-analysis detected by a simple, graphical test. BMJ. 1997;315:629-34.

31. Tierney JF, Stewart LA, Ghersi D, Burdett S, Sydes MR. Practical methods for incorporating summary time-to-event data into meta-analysis. Trials. 2007; 8(1):16. https://doi.org/10.1186/1745-6215-8-16.

32. William $\mathrm{G}$. Cochran. The combination of estimates from different experiments. Biometrics. 1954;10:101-29.

33. Higgins JP, Thompson SG, Deeks JJ, Altman DG. Measuring inconsistency in meta-analyses. BMJ. 2003;327:557-60.

34. Pavasini R, Biscaglia S, Barbato E, Tebaldi M, Dudek D, Escaned J, et al. Complete revascularization reduces cardiovascular death in patients with ST-segment elevation myocardial infarction and multivessel disease: systematic review and meta-analysis of randomized clinical trials. Eur Heart J. 2019:41(42):4103-10.

35. Begg CB, Mazumdar M. Operating characteristics of a rank correlation test for publication bias. Biometrics. 1994:4:1088-101.

36. Yang W, Chen MH, Wang MQ, Cui M, Gao W, Wu W, Wu JY, Dai Y, Yan K. Combination therapy of radiofrequency ablation and transarterial chemoembolization in recurrent hepatocellular carcinoma after hepatectomy compared with single treatment. Hepatol Res. 2009:39(3):23140. https://doi.org/10.1111/j.1872-034X.2008.00451.x.

37. Morimoto M, Numata K, Kondou M, Nozaki A, Morita S, Tanaka K. Midterm outcomes in patients with intermediate-sized hepatocellular carcinoma: a 
randomized controlled trial for determining the efficacy of radiofrequency ablation combined with transcatheter arterial chemoembolization. Cancer. 2010;116(23):5452-60. https://doi.org/10.1002/cncr.25314.

38. Peng ZW, Zhang YJ, Liang HH, Lin XJ, Guo RP, Chen MS. Recurrent hepatocellular carcinoma treated with sequential transcatheter arterial chemoembolization and RF ablation versus RF ablation alone: a prospective randomized trial. Radiology. 2012;262(2):689-700. https://doi.org/10.1148/ra diol.11110637.

39. Lin JJ, Wu W, Jiang XF, Jin XJ, Lu LJ, Bao LW. Clinical outcomes of radiofrequency ablation combined with transcatheter arterial chemoembolization for the treatment of hepatocellular carcinoma: a singlecenter experience. Zhonghua zhong liu za zhi. 2013;35:144-7.

40. Peng ZW, Zhang YJ, Chen MS, Xu L, Liang HH, Lin XJ, et al. Radiofrequency ablation with or without transcatheter arterial chemoembolization in the treatment of hepatocellular carcinoma: a prospective randomized trial. J Clin Oncol. 2013;31:426-32.

41. Liu HC, Shan EB, Zhou L, Jin H, Cui PY, Tan Y, et al. Combination of percutaneous radiofrequency ablation with transarterial chemoembolization for hepatocellular carcinoma: observation of clinical effects. Chinese J Cancer Res. 2014;26:471-7.

42. Yin X, Zhang L, Wang YH, Zhang BH, Gan YH, Ge NL, et al. Transcatheter arterial chemoembolization combined with radiofrequency ablation delays tumor progression and prolongs overall survival in patients with intermediate (BCLC B) hepatocellular carcinoma. BMC Cancer. 2014;14:849.

43. Gao F, Pang ZG, Han B, Chen WC, Huang GF. Transcatheter hepatic arterial chemoembolization combined with radiofrequency ablation for large hepatocellular carcinomas: clinical analysis of therapeutic efficacy and survival rate. J Intervent Radiol. 2016;25(04):316-9.

44. Hyun D, Cho SK, Shin SW, Park KB, Park HS, Choo SW, et al. Early stage hepatocellular carcinomas not feasible for ultrasound-guided radiofrequency ablation: comparison of transarterial chemoembolization alone and combined therapy with transarterial chemoembolization and radiofrequency ablation. Cardiovasc Intervent Radiol. 2016;39:417-25.

45. Shi C-S, Yang Q, Qiao B-B, Yu X-X, Zheng B-R, Li C, et al. Radiofrequency ablation for the treatment of hepatic residuallesions after TACE: analysis of curative effect. J Intervent Radiol. 2016;25(12):1097-100.

46. Song MJ, Bae SH, Lee JS, Lee SW, Song DS, You CR, et al. Combination transarterial chemoembolization and radiofrequency ablation therapy for early hepatocellular carcinoma. Korean J Intern Med. 2016;31:242-52.

47. Tang C, Shen J, Feng W, Bao Y, Dong X, Dai Y, et al. Combination therapy of radiofrequency ablation and transarterial chemoembolization for unresectable hepatocellular carcinoma: a retrospective study. Medicine. 2016;95:e3754

48. Kim MY, Jin WK, Myung DS, Jun CH, Cho SB. Outcomes of transarterial chemoembolization with or without additional radiofrequency ablation in hepatocellular carcinoma of 2 to $5 \mathrm{~cm}$ in diameter. Iranian J Radiol. 2016. In Press.

49. Nan Zhu, L. U. Dong, Jingkun Xiao, Lyu Weifu. Efficacy of transcatheter arterial chemoembolization combined with radiofrequency ablation in advanced hepatocellular carcinoma patients. Chin J Intervent Imaging Ther. 2017;14(04):195-9.

50. Shimose S, Tanaka M, Iwamoto H, Niizeki T, Shirono T, Aino H, et al. Prognostic impact of transcatheter arterial chemoembolization (TACE) combined with radiofrequency ablation in patients with unresectable hepatocellular carcinoma: Comparison with TACE alone using decision-tree analysis after propensity score matching. J Soc Hepatol. 2019;49:919-28.

51. Liu F, Chen M, Mei J, Xu L, Guo R, Lin X, et al. Transarterial chemoembolization combined with radiofrequency ablation in the treatment of stage B1 intermediate hepatocellular carcinoma. J Oncol.2019; 2019:6298502.

52. Lee H, Yoon CJ, Seong NJ, Jeong SH, Kim JW. Comparison of combined therapy using conventional chemoembolization and radiofrequency ablation versus conventional chemoembolization for ultrasound-invisible early-stage hepatocellular carcinoma (Barcelona Clinic Liver Cancer Stage 0 or A). Korean J Radiol. 2018;19:1130-39.

53. Chu HH, Kim JH, Yoon HK, Ko HK, Gwon DI, Kim PN, et al. Chemoembolization combined with radiofrequency ablation for mediumsized hepatocellular carcinoma: a propensity-score analysis. J Vasc Interv Radiol. 2019;30:1533-43.

54. Endo K, Kuroda H, Oikawa T, Okada Y, Fujiwara Y, Abe T, et al. Efficacy of combination therapy with transcatheter arterial chemoembolization and radiofrequency ablation for intermediate-stage hepatocellular carcinoma. Scand J Gastroenterol. 2018:53:1575-83.

55. Yi PS, Huang $M$, Zhang $M, X u L, X u M Q$. Versus comparison of transarterial chemoembolization combined with radiofrequency ablation therapy surgical resection for early hepatocellular carcinoma. Am Surg. 2018;84:282-88.

56. Kishore S, Friedman T, Madoff DC. Update on embolization therapies for hepatocellular carcinoma. Curr Oncol Rep. 2017;19:40.

57. Sergio A, Cristofori C, Cardin R, Pivetta G, Ragazzi R, Baldan A, et al. Transcatheter arterial chemoembolization (TACE) in hepatocellular carcinoma ( $\mathrm{HCC})$ : the role of angiogenesis and invasiveness. Am J Gastroenterol. 2008;103:914-21.

58. Wang B, Xu H, Gao ZQ, Ning HF, Sun YQ, Cao GW. Increased expression of vascular endothelial growth factor in hepatocellular carcinoma after transcatheter arterial chemoembolization. Acta radiologica (Stockholm, Sweden: 1987). 2008:49:523-9.

59. Li X, Feng GS, Zheng CS, Zhuo CK, Liu X. Influence of transarterial chemoembolization on angiogenesis and expression of vascular endothelial growth factor and basic fibroblast growth factor in rat with Walker-256 transplanted hepatoma: an experimental study. World J Gastroenterol. 2003; 9:2445-9.

60. Takayasu K. Transarterial chemoembolization for hepatocellular carcinoma over three decades: current progress and perspective. Japanese J Clin Oncol. 2012;42:247-55.

61. Bruix J, Sherman M. Management of hepatocellular carcinoma. Hepatology (Baltimore, Md.). 2005;42:1208-36.

62. Mazzaferro V, Battiston C, Perrone S, Pulvirenti A, Regalia E, Romito R, et al. Radiofrequency ablation of small hepatocellular carcinoma in cirrhotic patients awaiting liver transplantation: a prospective study. Ann Surg. 2004; 240:900-9.

63. Rossi S, Garbagnati F, Lencioni R, Allgaier HP, Marchianò A, Fornari F, et al. Percutaneous radio-frequency thermal ablation of nonresectable hepatocellular carcinoma after occlusion of tumor blood supply. Radiology. 2000;217:119-26.

64. Ahmed M, Goldberg SN. Combination radiofrequency thermal ablation and adjuvant IV liposomal doxorubicin increases tissue coagulation and intratumoural drug accumulation. Int J Hyperthermia. 2004;20:781-802.

65. Takaki H, Yamakado K, Nakatsuka A, Fuke H, Murata K, Shiraki K, et al. Radiofrequency ablation combined with chemoembolization for the treatment of hepatocellular carcinomas $5 \mathrm{~cm}$ or smaller: risk factors for local tumor progression. J Vasc Interv Radiol. 2007;18:856-61.

66. Takayasu K, Wakao F, Moriyama N, Muramatsu Y, Sakamoto M, Hirohashi S, et al. Response of early-stage hepatocellular carcinoma and borderline lesions to therapeutic arterial embolization. Am J Roentgenol. 1993;160:301-6.

67. Monsky WL, Kruskal JB, Lukyanov AN, Girnun GD, Ahmed M, Gazelle GS, et al. Radio-frequency ablation increases intratumoral liposomal doxorubicin accumulation in a rat breast tumor model. Radiology. 2002;224:823-9.

68. Ako S, Nakamura S, Nouso K, Dohi C, Wada N, Morimoto Y, et al. Transcatheter arterial chemoembolization to reduce size of hepatocellular carcinoma before radiofrequency ablation. Acta Med Okayama. 2018;72:4752.

69. Wang X, Hu Y, Ren M, Lu X, Lu G, He S. Efficacy and safety of radiofrequency ablation combined with transcatheter arterial chemoembolization for hepatocellular carcinomas compared with radiofrequency ablation alone: a time-to-event meta-analysis. Korean J Radiol. 2016;17:93-102.

70. Chen QW, Ying HF, Gao S, Shen YH, Meng ZQ, Chen H, et al. Radiofrequency ablation plus chemoembolization versus radiofrequency ablation alone for hepatocellular carcinoma: A systematic review and metaanalysis. Clin Res in Hepatol Gastroenterol. 2016;40:309-14.

\section{Publisher's Note}

Springer Nature remains neutral with regard to jurisdictional claims in published maps and institutional affiliations. 